\title{
Ciencias, humanidades y artes en la educación del profesional universitario
}

Profesor emérito, Profesor extraordinario investigador. Facultad de Estomatología. Universidad Peruana Cayetano Heredia.
Beltrán-Neira RJ. Ciencias, humanidades y artes en la educación del profesional universitario. Rev Estomatol Herediana. 2009; 19(2):131-132.
"..., hasta en el gran molar cuya encía late en aquel lácteo hoyuelo que inadvertido lábrase y pulula..."

Esta no es la descripción de un experto en patología o cirugía bucal. Son líneas de la poesía Tahona Estuosa de César Vallejo, Trilce XXIII.

El profesional universitario está llamado a ser un líder del desarrollo social, económico y cultural de su país. Para poder actuar con eficacia profesional en un determinado contexto social y cultural, el graduado de una universidad debe ser eficaz tanto en el desempeño de las competencias que conforman su perfil profesional, como en poder incorporarse culturalmente al medio donde actúa, es decir, integrarse en el mundo complejo que conforman las profesiones, los técnicos, los artistas, y el ser de los hombres y mujeres que habitan en la ciudad y en el campo.

Además, en un país multicultural y multilingüe como el Perú, la educación del universitario debe facilitar su actuación en medios distintos, donde el castellano no es la lengua materna.

Esta incorporación requiere, además del bagaje de conocimientos científicos y técnicos, el desarrollo afectivo que facilite su relacionamiento con personas de diferentes niveles educativos. La formación de la sensibilidad, que comienza muy temprano en el hogar, debe tener oportunidades de crecimiento en la escuela primaria y en el colegio secundario. Son años propicios para la formación de los afectos, para la comunicación con otros y la comprensión de las diferencias. El medio universitario donde se forma como profesional, debe proporcionar al alumno las bases científicas de la conducta humana, que sustentan el desarrollo de la afectividad, el empleo de la razón y el ejercicio de la voluntad.

Estamos hablando de una formación integral donde no existan barreras entre los campos del saber. Es la incorporación de la sensibilidad estética y ética mediante el contacto con las humanidades, las ciencias y las artes en un medio donde se cultivan los valores democráticos.

Con este bagaje en el ser y en el modo de ser, el ejercicio profesional será un transitar gozoso en lo personal y una actividad de profunda significación social. El profesional resultará integrado al esfuerzo nacional por una vida mejor donde el respeto de los derechos de los demás forme parte de la conducta de todos los días.

No puede haber desarrollo personal sin una filosofía de vida. Las humanidades ponen al alumno en contacto con las grades corrientes de pensamiento en torno a los problemas del hombre y de la sociedad. La filosofía y las ciencias sociales deben servir de matriz valorativa para el desempeño personal y profesional en la vida.

Nuestra Facultad, desde su fundación, buscó las mejores formas de lograr la tan deseada formación integral. Se tropezó con los prejuicios y la incomprensión de profesores y alumnos, cuya educación básica los traía encasillados en compartimentos y en preferencias vocacionales más bien prejuiciosas y emocionales por las ciencias o por las humanidades; las artes, para la gran mayoría, quedaban fuera de todo interés para una dedicación profesional. En los estudios generales o ciclo básico, los alumnos de nuestra universidad, orientados hacia la ciencia, no mostraban interés ni prestaban seria atención a los cursos de humanidades y artes, respecto a los cuales venían mal dispuestos.

Debido a esta constatación decidimos introducir un plan curricular que evitara la superposición en el tiempo de los cursos preferidos y de los cursos minusvalorados por el alumnado. Así mismo, introdujimos la extensión de las humanidades, ciencias sociales y las artes a lo largo de toda la carrera, con espacios curriculares específicos, pero buscando el relacionamiento con los cursos profesionales. En este empeño, hay que reconocer que, en general, la limitada participación del profesorado en las disciplinas no 
estrictamente profesionales dificultó la acogida que debía merecer, la presencia de profesores de humanidades ciencias sociales y artes en los años de formación profesional.

Hasta el presente los resultados del esfuerzo realizado para lograr una formación integral del odontólogo no han sido medidos con instrumentos apropiados, instrumentos que no solo exploren la retención de información, si no que, principalmente, traten de reconocer el efecto en los aspectos valorativos de la conducta de los nuevos profesionales, y su disposición frente a las exigencias del desarrollo social y el mejoramiento equitativo de las condiciones de vida de la población en general. En otras palabras, que exploren el grado de madurez personal y profesional que el medio universitario hubiera sido capaz de estimular.

Seguiremos en la búsqueda de mejores enfoques y medios educativos más eficaces, ahora aprovechando el potencial de los sistemas de informática. Tenemos que seguir innovando los modelos de enseñanza-aprendizaje-evaluación, hoy que contamos con información sobre cómo opera el cerebro humano, gracias a los grandes avances de las neurociencias. Sabemos que mediante el ejercicio de la voluntad es posible modificar los patrones de funcionamiento neuronal. La educación de la voluntad surge como un nuevo reto en la educación del hombre contemporáneo. La universidad tiene en sus manos los recursos básicos para realizar una investigación educativa que se nutra de los nuevos conocimientos que la ciencia viene aportando, para lo cual es indispensable el trabajo multidisciplinario.

El reto está planteado, tenemos jóvenes profesores que pueden emplearse en investigaciones educativas de largo alcance, contamos con un contingente valioso de alumnos con quienes se pueden ensayar nuevos enfoques y aplicar tecnologías que también debemos contribuir a crear. El único recurso, realmente transformador que tenemos para mejorar la educación, desde sus raíces, es la investigación en todas sus formas y la reflexión compartida en torno a sus resultados. 